\title{
Trends in Instrument Flight Rules (IFR) Conditions at Major Airports in the United States
}

\author{
SCOTT E. STEVENS \\ Cooperative Institute for Climate and Satellites-North Carolina, North Carolina \\ State University, Asheville, North Carolina
}

(Manuscript received 14 November 2018, in final form 17 January 2019)

\begin{abstract}
Weather-related delays are among the most common in aviation and are frequently the result of low visibility or cloud ceilings, which cause landing aircraft to be spaced farther apart for safety, reducing the capacity of an airport to land aircraft in a timely fashion. Using 45 years of archived surface observations from 30 of the busiest airports across the United States, the prevalence of low-visibility and low-ceiling conditions is examined, along with the meteorological conditions that support them and the associated trends over time. It is shown that these conditions are becoming less frequent at most locations — for many significantly so-and that this decrease can be seen at all times of day and in all seasons.
\end{abstract}

\section{Introduction}

As the demand for air travel continues to increase with a growing population, more congested airspace surrounding large airports can result in delays to travelers and billions in lost revenue by airlines. In 2007, air carrier delays cost the industry as much as $\$ 32$ billion, and lowered the GDP of the U.S. economy by $\$ 4$ billion (Ball et al. 2010). Weather remains a considerable source of aircraft delays and was responsible for over one-half of delays during 2016 (Bureau of Transportation Statistics 2004). Among weather-related delays are low visibility and cloud ceilings, which cause arriving aircraft to navigate by instruments rather than visually. The inability of pilots to visually separate themselves from other aircraft reduces an airport's arrival capacity, as controllers must keep aircraft separated by a larger distance. In addition, such conditions increase the possibility that an aircraft will ultimately have to divert to an alternate destination, thus requiring them to preload additional fuel, increasing weight and cost, to allow them to reach this alternate airport.

\section{a. Separation minima}

In the United States, the Federal Aviation Administration (FAA) governs the process by which aviation operations are conducted. When low cloud ceilings and/or

Corresponding author: Scott E. Stevens, scott@cicsnc.org low visibility prevent pilots from navigating or avoiding collisions visually, an aircraft must be operated by reference to instruments alone, flying under what is known as instrument flight rules (IFR). Separation from terrain, obstacles, and other aircraft is provided by air traffic controllers utilizing radar at facilities along an aircraft's entire route of flight. During the critical final phase of flight, as an aircraft approaches the destination airport, visual separation from the ground and other arriving aircraft is possible if the aircraft is clear of clouds and visibility is sufficient (FAA 2017, part 7-4-2). However, when this is not possible, air traffic controllers must rely on radar to keep aircraft separated, and a by-product of this is that a larger separation distance must be maintained.

\section{b. Parallel runway arrivals}

During IFR operations, in addition to expanded spacing in trail, aircraft must be separated laterally by a larger distance. At airports with parallel runways, this can have a large impact on their capacity for arriving aircraft. When operating under visual flight rules (VFR) two runways need only be separated by $700 \mathrm{ft}(1 \mathrm{ft}=$ $30.48 \mathrm{~cm}$ ) to accommodate parallel approaches. However, under IFR, this distance is increased to $4300 \mathrm{ft}$, with certain exceptions down to $3000 \mathrm{ft}$ (FAA 2012). At many airports, particularly in densely populated areas where this design is not possible, this means that simultaneous parallel approaches become impossible during low-visibility or low-ceiling events. As an example, 
San Francisco International Airport (SFO) is able to land as many as 54 aircraft per hour during visual conditions, but this number is reduced to, at best, 36 per hour during instrument conditions, $\mathrm{a}^{1 / 3} \mathrm{3}$ reduction in capacity (FAA 2018).

\section{c. Meteorological conditions}

Nearly all low-visibility events are caused by some form of moisture in the air (Clark 1995), whether fog and precipitation at the surface, or low cloud ceilings overhead. Fog has been found to be a phenomenon on the decline in numerous locations around the world (Belorid et al. 2015; Vautard et al. 2009; Sachweh and Koepke 1995), a trend attributed to both rising temperatures, which reduce the likelihood of saturation, and improving air quality, which reduces the quantity of condensation nuclei in the air (Klemm and Lin 2016). Increasing urbanization has also been tied to a decrease in fog and higher cloud ceilings in Southern California (Williams et al. 2015), the result of higher nighttime low temperatures and a larger spread between temperature and dewpoint, also known as dewpoint depression. The densest fog, with visibilities of less than $0.25 \mathrm{mi}(1 \mathrm{mi}=$ $1609 \mathrm{~m}$ ), has all but disappeared in Los Angeles, California (LaDochy and Witiw 2012). This is particularly of interest to this study, which focuses only on the busiest, and therefore especially urbanized, airports in the United States.

Dense fog tends to occur only when the dewpoint depression is less than approximately $1^{\circ} \mathrm{C}$ and wind speeds are low (Croft et al. 1997). Trends in surface relative humidity over the United States are weak and not spatially uniform (Brown and DeGaetano 2013), and have been found to be slightly increasing inland while decreasing over the ocean (Dai 2006). Because of the variation in moisture in space and time, one may assume that the incidence of low-visibility events would vary accordingly, and possibly change with a changing climate as moisture profiles are altered. As we see both temperatures and absolute moisture content rising (Willett et al. 2007; Held and Soden 2006; Trenberth et al. 2005), the outcome of this relationship has a strong impact on the prevalence of low-visibility events.

While the above work has investigated trends in reduced visibility and fog in localized areas, the author is unaware of any studies that cover an area as large as the continental United States or that examine these conditions with a focus on aviation impacts. This study investigates these low-visibility events, how their frequency varies in space and time, and whether there exist associated trends over several decades. Archived surface conditions collected by both human observers and automated sensors at airports across the United States are used to identify IFR conditions and determine whether there are significant changes in their prevalence over time.

\section{Data and methods}

Surface observations were retrieved for the 30 busiest airports in the United States for the period 1973-2017 from the Iowa Environmental Mesonet (https://mesonet. agron.iastate.edu/request/download.phtml). All but two of the 30 airports studied have a record that is more than 95\% complete over the study period; records for Denver, Colorado, and Austin, Texas, did not begin until July of 1996. Prior to the 1990s, measurements were performed mainly by trained human observers. Since then, the Automated Surface Observing System (ASOS) has become the dominant method of determining surface conditions at airports. The change in method resulted in a number of discontinuities in data, particularly with regard to cloud cover. ASOS tends to see less cloud cover, primarily because observations stop at $12000 \mathrm{ft}$ above ground level, regarding any clouds above this level as a clear sky (Dai et al. 2006). For this reason, ASOS is considered to be a poor dataset for measuring climatic trends. However, this study focuses specifically on overcast and broken cloud layers at low altitude, and Sun and Groisman (2004) found that ASOS does reliably report cloud cover of this particular type.

Airport weather conditions are typically recorded once each hour, just before the top of the hour. During periods of significant weather, which often coincide with IFR conditions, special observations are taken at other times during the hour. To avoid the introduction of bias toward IFR conditions, only the last observation during a given hour was considered. Only observations that included valid measurements of temperature, dewpoint, cloud ceiling, and visibility were included. Dewpoint measurements should be taken with caution, because a sensor change in the mid-2000s at ASOS stations (Lin and Hubbard 2004) is associated with a marked decrease in high dewpoint values.

\section{a. Determining IFR conditions}

For each observation, the reported cloud ceiling and visibility were considered. Cloud ceiling is defined as the lowest level of broken or overcast cloud cover ( $5 / 8$ of sky or greater coverage). Air traffic regulations state that an aircraft may only be vectored for a visual approach if the reported visibility at the airport is at least 3 (statute) $\mathrm{mi}$ and the cloud ceiling is at least $500 \mathrm{ft}$ higher than the minimum vectoring altitude (FAA 2017, section 7-4-2), which varies by airport but generally translates to approximately $2500 \mathrm{ft}$ above the airport elevation. An observation was flagged for IFR cloud cover if the 
TABLE 1. Contingency table for low visibility and low dewpoint depression (all locations; 1973-2000).

\begin{tabular}{llll}
\hline \hline & Visibility $<3$ mi & Visibility $\geq 3$ mi & Total \\
\hline Dewpoint depression $<3^{\circ} \mathrm{C}$ & $A=284865$ & $B=1818170$ & 2103035 \\
Dewpoint depression $\geq 3^{\circ} \mathrm{C}$ & $C=15943$ & $D=4646938$ & 4662881 \\
Total & 300808 & 6465108 & 6765916 \\
\hline
\end{tabular}

ceiling was less than $2500 \mathrm{ft}$ above ground level (AGL) and was flagged for IFR visibility if the reported visibility was less than 3 (statute) mi. The presence of either of these conditions generally causes an airport to operate under IFR. In practice, local influences (e.g., terrain or other airports) introduce some variation in these general guidelines, and air traffic controllers have latitude in their judgment to begin assigning instrument approaches on the basis of pilot reports from other aircraft. However, in an effort to remove local variation and focus only on the weather conditions, uniform criteria for visibility and cloud ceiling have been employed here.

\section{b. Changes in IFR conditions over time}

To investigate the change in IFR conditions over time, a Theil-Sen regression was performed between the year of study and the total number of IFR hours recorded that year, broken down by visibility, ceiling, or both, for each station in the study. Using Kendall's tau, statistical significance was assessed for the relationship between year and number of IFR hours. The diurnal and seasonal patterns in IFR frequency were compared at the beginning, middle, and end of the study period to examine the distribution of any change across time of day or time of year.

\section{c. Investigation of near-saturated atmosphere}

Because IFR conditions are so frequently associated with moisture at the surface, a comparison was made between observed IFR conditions and the spread between surface temperature and dewpoint (dewpoint depression). A contingency table was created for the incidence of low surface visibility $(<3 \mathrm{mi})$ and low dewpoint depression $\left(<3^{\circ} \mathrm{C}\right)$ (Table 1$)$. From this table, an odds ratio was calculated as $(A / B) /(C / D)$, providing a measure of the intersectionality of these conditions.

\section{Results}

\section{a. Overall IFR conditions}

The occurrence of IFR conditions over the period of study ranges from less than $1 \%$ at Las Vegas, Nevada, and Phoenix, Arizona, to over 23\% at San Diego, California. The more humid east experiences IFR conditions consistently more frequently than the drier interior west

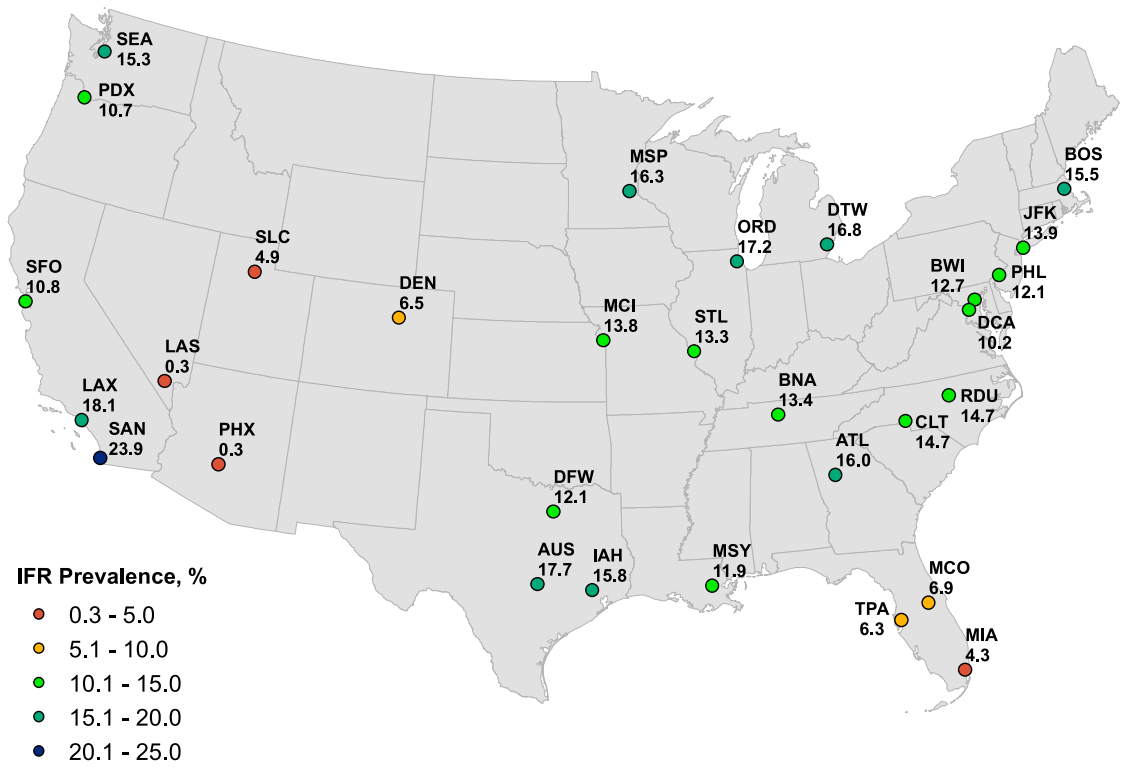

FIG. 1. Overall prevalence (\%) of IFR conditions at 30 airports selected for study (1973-2017) 


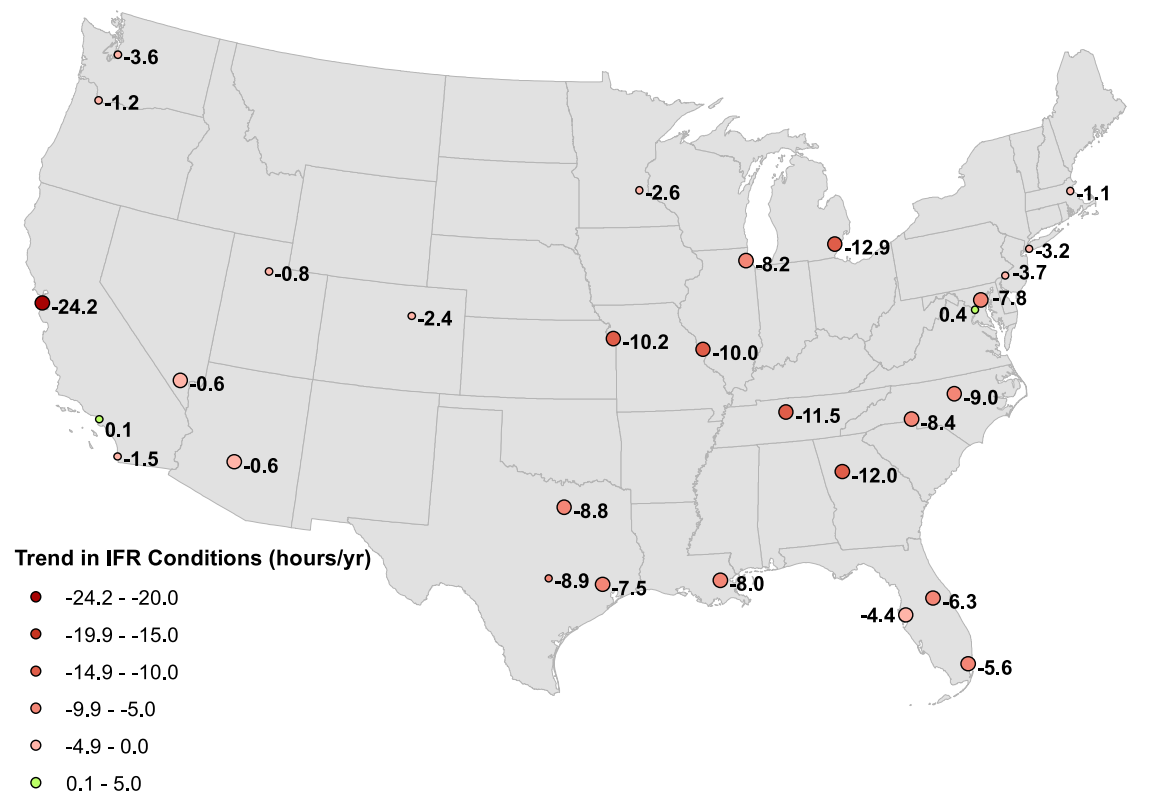

FIG. 2. Annual trend in frequency of IFR conditions $\left(\mathrm{h} \mathrm{yr}^{-1} ; 1973-2017\right)$. Larger points indicate those trends that are statistically significant at $95 \%$ level.

(Fig. 1). Of the 30 airports studied, 28 show a decreasing trend in IFR incidence, with 18 of those 28 being significant at the $95 \%$ level, mostly in the southeastern United States (Fig. 2). The magnitude of this trend ranges from nearly 0 to as much as $24 \mathrm{~h} \mathrm{yr}^{-1}$ at San Francisco, California, which has seen a decrease from nearly $1500 \mathrm{IFR} \mathrm{hyr}^{-1}$ to fewer than 500 since 1973. Over the period of study, this trend is highly impactful, with 16 of the 30 airports seeing a greater-than- $25 \%$ reduction in IFR hours.

\section{b. Daily variability}

Over the course of a day, IFR conditions are far more prevalent during the early morning hours, when temperature is at a minimum and saturated air is more likely (Fig. 3). Over the study period, the frequency of IFR conditions has decreased uniformly at all times of day, excepting a slightly larger decrease in the morning hours, when these conditions are the most prevalent. The proportional impact is thus largest in the evening, when the change amounts to a roughly $1 / 4$ reduction in IFR conditions over the study period.

\section{c. Seasonal variability}

Seasonally, IFR conditions are more common during the winter months, occurring roughly 2 times as frequently in January and December as in June and July (Fig. 4). As before, the associated decrease in IFR frequency can be seen in all seasons, although the drop appears to be more pronounced during the summer months (as much as $1 / 3$ ), when IFR conditions are already the least common.

\section{d. IFR conditions by cause}

IFR conditions are most often the result of low cloud ceilings, rather than low visibility at the surface (Fig. 5). However, while the incidence of both low ceiling and low visibility has decreased, the more notable decrease in frequency is associated with low surface visibility. These occurrences have decreased by roughly $50 \%$ since the mid-1970s. The tendency for IFR conditions to occur both in the morning hours and during the winter months suggests that, as found in Croft et al. (1997), high relative

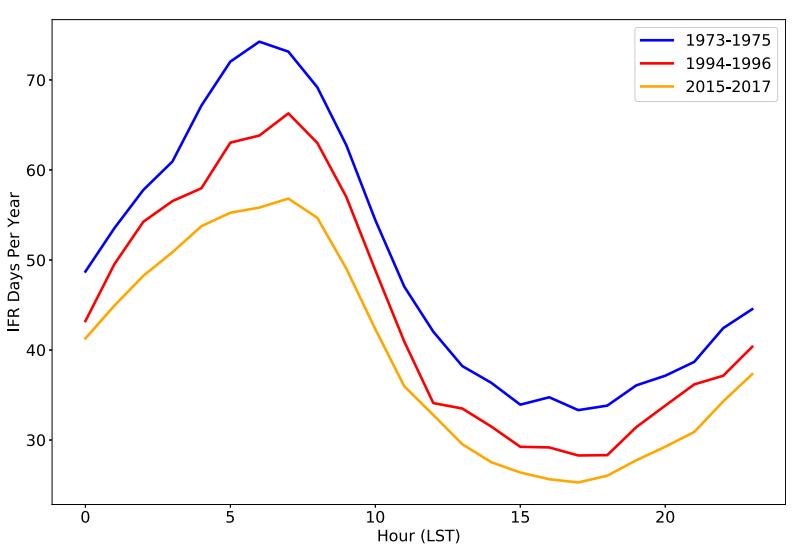

FIG. 3. Total IFR days per year (all locations) by local solar time (beginning, middle, and end of study period). 


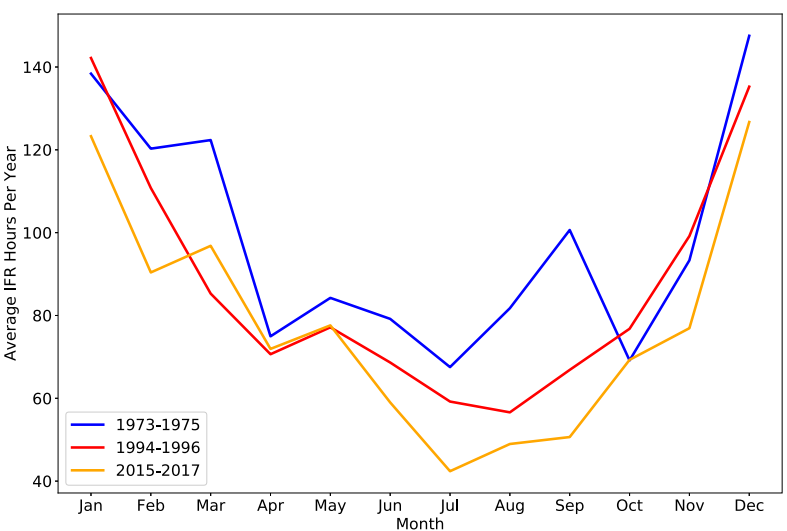

FIG. 4. Average IFR hours per year (all locations) by month (beginning, middle, and end of study period).

humidity is often a requisite condition for low visibility. Following their conclusions, which found that fog tends to occur only during times of very low dewpoint depression, the prevalence of these occurrences of near saturation was examined. Table 1 yields an odds ratio of approximately 46, meaning that the likelihood of low visibility occurring in high-humidity situations is approximately 46 times that outside those situations. Because of the aforementioned discontinuity with dewpoint observations that occurred with the switch to ASOS, these numbers were calculated only for the period from 1973 to 2000.

Temperature alone was examined during the same low-visibility conditions, and it was found that nearly all cases of low visibility occur when the surface temperature is less than $23^{\circ} \mathrm{C}$, and this threshold does not appear to be changing over time (Fig. 6). In a gradually warming environment in which nighttime low temperatures are being especially affected (Karl et al. 1993; Easterling et al. 1997; Folland et al. 2001,108-109), this could result in fewer and fewer hours that meet this threshold.

\section{Discussion and conclusions}

Across the country, at nearly every airport studied, the frequency with which IFR conditions are occurring is decreasing, and the trend is highly significant at more than half of those locations. The strongest and most significant changes are seen in the southeastern United States, where IFR conditions are decreasing at around $10-12 \mathrm{~h} \mathrm{yr}^{-1}$. A notable outlier is San Francisco, which has seen a decrease of $24 \mathrm{~h} \mathrm{yr}^{-1}$ over the period of study, amounting to a $70 \%$ decrease in the overall prevalence of IFR conditions since 1973 . Driven primarily by decreases in the occurrence of low visibility, the implication is a decrease in occurrences of weather-related delays due to aircraft separation requirements during

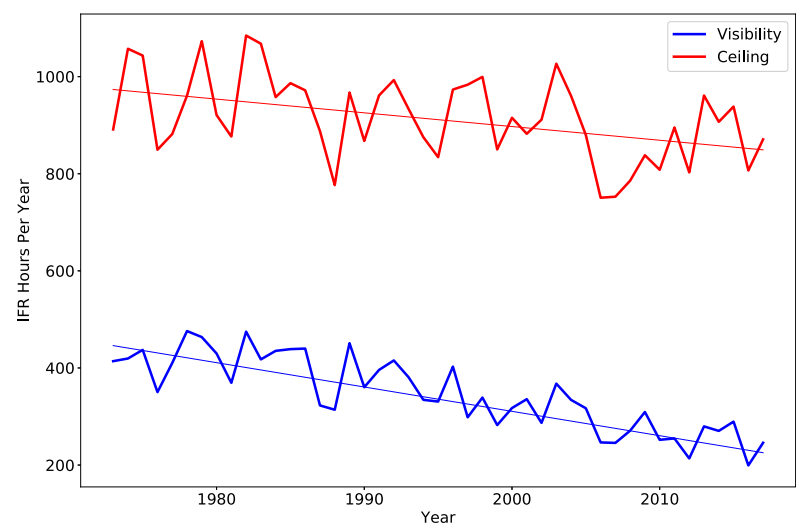

FIG. 5. Average number of IFR hours across all locations by year resulting from low visibility and low ceiling.

these periods. With some airports seeing more than a $50 \%$ reduction in the frequency of IFR conditions since 1973, it is becoming less common for arriving aircraft to be forced to rely on radar-based separation. As conditions allow for visual separation, aircraft can arrive more closely spaced and with greater frequency, alleviating congestion at the nation's busiest aerodromes and allowing airliners to depart with less reserve fuel, thus reducing weight, cost, and emissions.

Periods of low visibility are most frequently associated with a nearly saturated environment, resulting in visual obstruction due to fog, mist, rain, or snow. Previous work investigating fog suggests that these conditions are themselves becoming increasingly rare, due to a combination of the changing climate and increasing urbanization. The observations studied here support this conclusion, with low-visibility conditions found to be 46 times as likely during periods of near saturation as otherwise. A temperature below approximately $23^{\circ} \mathrm{C}$

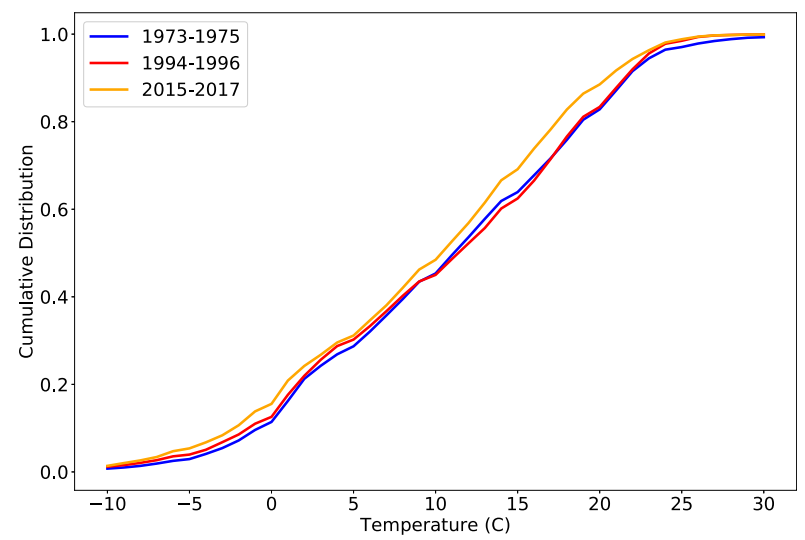

FIG. 6. Cumulative distribution of observed temperatures during periods of low visibility at all locations at the beginning, middle, and end of the study period. 
appears to be a requisite condition for low visibility to occur, a benchmark which has remained constant over the study period. Since a warming climate implies fewer and fewer hours which meet this condition, IFR conditions across the United States may continue to become less frequent.

Acknowledgments. This work was supported by NOAA through the Cooperative Institute for Climate and Satellites-North Carolina under Cooperative Agreement NA14NES432003. The author thanks Jared Rennie and Katharine Johnson for their input throughout the study process.

\section{REFERENCES}

Ball, M., and Coauthors, 2010: Total delay impact study: A comprehensive assessment of the costs and impacts of flight delay in the United States. National Center of Excellence for Aviation Operations Research Rep., 89 pp., http://www.nextor.org/ pubs/TDI_Report_Final_11_03_10.pdf.

Belorid, M., C. Lee, J.-C. Kim, and T.-H. Cheon, 2015: Distribution and long-term trends in various fog types over South Korea. Theor. Appl. Climatol., 122, 699-710, https://doi.org/10.1007/ s00704-014-1321-x.

Brown, P. J., and A. T. DeGaetano, 2013: Trends in U.S. surface humidity, 1930-2010. J. Appl. Meteor. Climatol., 52, 147-163, https://doi.org/10.1175/JAMC-D-12-035.1.

Bureau of Transportation Statistics, 2004: Airline on-time statistics and delay causes. U.S. Dept. of Transportation, accessed 26 January 2018, https://www.transtats.bts.gov/OT_Delay/ ot_delaycause1.asp.

Clark, D. A., 1995: Characterizing the causes of low ceiling and visibility at U.S. airports. Preprints, Sixth Conf. on Aviation Weather Systems, Dallas, TX, Amer. Meteor. Soc., 325-330.

Croft, P. J., R. L. Pfost, J. M. Medlin, and G. A. Johnson, 1997: Fog forecasting for the southern region: A conceptual model approach. Wea. Forecasting, 12, 545-556, https://doi.org/10.1175/ 1520-0434(1997)012<0545:FFFTSR >2.0.CO;2.

Dai, A., 2006: Recent climatology, variability, and trends in global surface humidity. J. Climate, 19, 3589-3606, https://doi.org/ 10.1175/JCLI3816.1.

, T. R. Karl, B. Sun, and K. E. Trenberth, 2006: Recent trends in cloudiness over the United States: A tale of monitoring inadequacies. Bull. Amer. Meteor. Soc., 87, 597-606, https:// doi.org/10.1175/BAMS-87-5-597.

Easterling, D. R., and Coauthors, 1997: Maximum and minimum temperature trends for the globe. Science, 277, 364-367, https:// doi.org/10.1126/science.277.5324.364.
FAA, 2012: Airport design. FAA Advisory Circular AC 150/530013A, 322 pp., https://www.faa.gov/documentLibrary/media/ Advisory_Circular/150-5300-13A-chg1-interactive-201612.pdf.

_ 2017: Air traffic control. FAA Order JO 7110.65X, 614 pp., https://www.faa.gov/documentLibrary/media/Order/JO_7110.65X_ Air_Traffic_Control.pdf.

— 2018: SFO AAR [Airport Acceptance Rate]. FAA, accessed 20 July 2018, https:/www.fly.faa.gov/Information/west/zoa/ sfo/sfo_aar.htm.

Folland, C. K., and Coauthors, 2001: Observed climate variability and change. Climate Change 2001: The Scientific Basis, Cambridge University Press, 99-181.

Held, I. M., and B. J. Soden, 2006: Robust responses of the hydrological cycle to global warming. J. Climate, 19, 5686-5699, https://doi.org/10.1175/JCLI3990.1.

Karl, T. R., and Coauthors, 1993: A new perspective on recent global warming: Asymmetric trends of daily maximum and minimum temperature. Bull. Amer. Meteor. Soc., 74, 10071023, https://doi.org/10.1175/1520-0477(1993)074<1007: ANPORG $>2.0 . \mathrm{CO} ; 2$.

Klemm, O., and N.-H. Lin, 2016: What causes observed fog trends: Air quality or climate change? Aerosol Air Qual. Res., 16, 1131-1142, https://doi.org/10.4209/aaqr.2015.05.0353.

LaDochy, S., and M. Witiw, 2012: The continued reduction in dense fog in the Southern California region: Possible causes. Pure Appl. Geophys., 169, 1157-1163, https://doi.org/10.1007/ s00024-011-0366-3.

Lin, X., and K. G. Hubbard, 2004: Uncertainties of derived dewpoint temperature and relative humidity. J. Appl. Meteor., $\mathbf{4 3}$, 821-825, https://doi.org/10.1175/2100.1.

Sachweh, M., and P. Koepke, 1995: Radiation fog and urban climate. Geophys. Res. Lett., 22, 1073-1076, https://doi.org/ 10.1029/95GL00907.

Sun, B., and P. Ya. Groisman, 2004: Variations in low cloud cover over the United States during the second half of the twentieth century. J. Climate, 17, 1883-1888, https://doi.org/10.1175/ 1520-0442(2004)017<1883:VILCCO >2.0.CO;2.

Trenberth, K. E., J. Fasullo, and L. Smith, 2005: Trends and variability in column-integrated atmospheric water vapor. Climate Dyn., 24, 741-758, https://doi.org/10.1007/s00382-005-0017-4.

Vautard, R., P. Yiou, and G. J. van Oldenborgh, 2009: Decline of fog, mist and haze in Europe over the past 30 years. Nat. Geosci., 2, 115-119, https://doi.org/10.1038/ngeo414.

Willett, K. M., N. P. Gillet, P. D. Jones, and P. W. Thorne, 2007: Attribution of observed surface humidity changes to human influence. Nature, 449, 710-713, https://doi.org/10.1038/ nature 06207.

Williams, A. P., R. E. Schwartz, S. Iacobellis, R. Seager, B. I. Cook, C. J. Still, G. Husak, and J. Michaelsen, 2015: Urbanization causes increased cloud base height and decreased fog in coastal Southern California. Geophys. Res. Lett., 42, 15271536, https://doi.org/10.1002/2015GL063266. 